\title{
A POSSÍVEL AUSÊNCIA DO CONCEITO DE GÊNERO NA VISÃo DE PROFESSORAS DE ENSINO FUNDAMENTAL
}

\author{
Valéria Marta Nonato Fernandes MOKWA ${ }^{1}$ \\ Fátima Aparecida Coelho GONINI ${ }^{2}$ \\ Paulo Rennes Marçal RIBEIRO ${ }^{3}$
}

\begin{abstract}
RESUMO: Este artigo traz algumas reflexões sobre as concepções de gênero e homossexualidade abordadas na escola ppor um grupo de docentes. O trabalho é um recorte de um projeto denominado Corpo esse Desconhecido desenvolvido em uma escola do interior paulista. O estudo segue referenciado pela Teoria das Representações, objetivando apreender as representações sociais de oito docentes referente à questões relacionadas a gênero e homossexualidade expressas na escola. Para obtenção dos dados foi aplicado um questionário aberto e a redação de diário de campo fundamentado na metodologia da pesquisa etnográfica escolar. O material obtido foi categorizado e organizado em duas tabelas com respectivas unidades temáticas. A análise do material revelou que as professoras têm pouco conhecimento científico a respeito dos temas, possuindo representações sociais marcadas pela influência cultural, que dificulta a abordagem desses temas, e quando os abordam, é de maneira tímida, sem permitir reflexão e problematização. $O$ estudo sugere que elas estão impregnadas de valores sexistas em que há uma naturalização das diferenças de gênero, apesar de evidenciarem a necessidade de conversar e refletir a respeito do assunto. A homossexualidade aparece como difícil de ser compartilhada pois se referem a ela de forma estereotipada e discriminatória. As professoras reivindicaram a continuação do projeto ao tomar ciência de suas fragilidades diante das discussões dessas questões, revelando a necessidade de formação através de estudos que subsidiem a sua prática pedagógica. Depreende-se ser necessária a efetiva participação de todos os envolvidos nesse projeto para trabalhar as questões que atrelam o gênero e a homossexualidade.
\end{abstract}

PALAVRAS-CHAVE: Gênero. Heteronormatividade. Formação docente.

\section{Introdução}

A escola é apontada como um importante espaço de intervenção para se discutir questões a respeito da sexualidade; gênero; violência; drogas; entre outros temas de relevância social que demandam reflexão e discussão. Para se entender e discutir essas temáticas recorreu-se a construção histórico-cultural da sexualidade defendida nos estudos de Michel Foucault (1998, p.85), os quais mostram que as verdades de cada tempo são construções

\footnotetext{
${ }^{1}$ UNESP - Universidade Estadual Paulista. Faculdade de Ciências e Letras - Núcleo de Estudos da Sexualidade. Araraquara - SP- Brasil. 141800-901 - valeriamokwa@gmail.com

${ }^{2}$ UNESP - Universidade Estadual Paulista. Faculdade de Ciências e Letras - Núcleo de Estudos da Sexualidade. Araraquara - SP- Brasil. 141800-901. Escola Estadual José Carlos Donadeli Panice. Secretaria da Educação do Estado de São Paulo. Diretoria De Ensino. Franca - SP - Brasil. fatinini@yahoo.com.br

${ }^{3}$ UNESP - Universidade Estadual Paulista. Faculdade de Ciências e Letras - Departamento de Psicologia da Educação - Núcleo de Estudos da Sexualidade. Araraquara - SP- Brasil. 141800901 paulorennes@fclar.unesp.br
} 
históricas e, portanto, podem ser desconstruídas. O autor salienta que a sexualidade se reveste de relações de poder e de práticas discursivas e diz: "Nós somos controlados e normatizados por múltiplos processos de poder. Essa visão do poder também é vital para uma história da sexualidade [...]”.

Esse poder produz uma concepção do indivíduo como sujeito de uma sexualidade, ou seja, elege saberes e valores normatizantes, objetivando controlar e estabelecer regras e verdades em relação ao corpo e aos prazeres influenciando na construção da sexualidade dos indivíduos e o que se refere às questões de gênero e homossexualidade. De acordo com essas reflexões e considerando que a escola tem um importante papel na construção social de cada época, houve a intenção de introduzir assuntos como, sexualidade, violência, ética, saúde, meio ambiente no âmbito escolar, através dos Parâmetros Curriculares Nacionais (PCNs) instituídos em 1998 pelo Governo Federal, com o objetivo de estabelecer uma referência curricular nacional, por meio de Tema Transversal, objetivando tematizar problemas sociais que possuem um caráter grave e urgente que demandam ser trabalhados, sistematicamente, no espaço escolar (BRASIL, 1998).

Partindo desses pressupostos, sentiu-se a necessidade de apreender as representações das professoras em relação às questões relacionadas ao gênero e homossexualidade, expressas na escola. As hipóteses pairavam sobre as indagações de como são expressas as Representações Sociais (RS) das professoras em relação às temáticas e como estas tratam os temas juntamente com os (as) educandos (as). O material obtido foi categorizado e organizado em duas tabelas com respectivas unidades temáticas baseadas nos estudos de Bardin (1995).

Este estudo fundamentou-se a luz da Teoria das Representações Sociais (TRS), de Serge Moscovici (2003), e possibilitou compreender como é concebido o gênero e a homossexualidade nas representações expressas pelas docentes.

Para a realização dessa pesquisa, utilizou-se a metodologia fundamentada na etnografia em educação (ANDRÉ, 1995). Os dados foram obtidos através de questionário aberto e individual aplicado com cada participante durante o horário de trabalho pedagógico coletivo $^{4}$ (HTPC) contendo questões referentes ao gênero e homossexualidade e alguns dados sócio-demográficos, bem como, por meio de observações registradas em diário de campo, durante a permanência das (os) pesquisadores (as) na escola no primeiro semestre do ano de 2009 de segunda a sexta-feira no período de aula das 13h00min às 17h00min, em contato

\footnotetext{
${ }^{4}$ HTPC: algumas instituições escolares utilizam outra nomenclatura.
} 
próximo com o cotidiano escolar para observar a maneira como as questões de gênero e homossexualidade são representadas pelas docentes.

Louro, Scott, Kahhale, entre outros autores em seus estudos sobre as questões de gênero demonstram que a construção do ser "homem” e ser “mulher” são um processo social que sofre influências e se modifica com o decorrer dos tempos.

Kahhale (2001) salienta que o sexo social - portanto, o gênero - é uma das relações estruturantes que situa o indivíduo no mundo e determina, ao longo da sua vida, oportunidades, escolhas, trajetórias, vivências, lugares e interesses, ou seja, um produto da aprendizagem social.

Assim, desenvolveu-se essa pesquisa buscando apreender as representações das docentes de uma escola estadual do interior paulista frente às questões de gênero e homossexualidade. Vale ressaltar que este estudo é um recorte de um projeto maior realizado nessa instituição escolar desenvolvido desde o ano de 2005 pelos (as) pesquisadores (as), denominado Corpo Esse Desconhecido que visa abordar e trabalhar as questões da sexualidade humana, entre outros, temas relevantes, junto com as docentes, em um espaço específico para que as mesmas possam exteriorizar dúvidas, anseios, angústias e receios que possuem ao entrarem em contato com situações relativas a essas temáticas. Nesse intento, se utiliza dinâmicas para promover a sensibilização e a reflexão desses assuntos, bem como, oficinas para se discutir maneiras de se trabalhar os temas na sala de aula e promover a autoreflexão da prática profissional.

Figueiró (2006) avalia que a forma pela qual conduziu a proposta de formação continuada de educadores sexuais, firmada em um modelo reflexivo, comprova a eficácia da reflexão como instrumento de desenvolvimento do pensamento e da ação. A atenção à prática dos docentes consistiu em um pano de fundo das reflexões e o conhecimento reconstruído retroalimentava-a. Assim, faz-se necessário que sejam abertos espaços de discussões e reflexões sobre Sexualidade, para que temores sejam confessados e receios dissipados.

Percebe-se que no decorrer do desenvolvimento do projeto houve avanços nas atitudes e comportamentos das professoras em relação às questões trabalhadas que atrelam a sexualidade na prática docente, pois, estas ressaltam que atualmente conduzem questões que atrelam à temática com naturalidade, o que denota a reconstrução de suas representações em relação aos temas desenvolvidos. As professoras continuam enfatizando que há muito para se discutir, visto que, as questões e situações que surgem no espaço escolar, são vastas e suscitam análises, reflexões e estudos para se conseguir vencer os entraves e desafios, principalmente, em relação ao gênero e a homossexualidade. 
Desta forma, se faz necessário a continuidade desse estudo para levantar dúvidas, dificuldades e anseios das docentes a respeito das questões de gênero, bem como, criar subsídios que contribuam para a auto-reflexão, conscientização e possibilite uma prática docente livre de preconceitos.

No seu conjunto, a pesquisa procurou descrever o sistema de significados culturais próprios ao grupo das professoras, considerando que o comportamento humano é significativamente, influenciado pelo contexto em que se situa. Para Ludke e André (1986, p.15), é “[...] quase impossível entender o comportamento humano sem tentar entender o quadro referencial dentro do quais os indivíduos interpretam seus pensamentos, sentimentos e ações [...]”.

No decorrer do estudo, várias dificuldades foram mencionadas pelas educadoras constituindo-se barreiras para se abordar às questões de gênero e a homossexualidade na sala de aula. Pressupõe que os entraves são causados pela influencia do contexto sócio-cultural que os sujeitos trazem arraigados na sua constituição dificultando as discussões que contemplem a formação de identidades sexuais, de gênero e a homossexualidade.

Assim, espera-se que esse trabalho suscite reflexões para que o tema seja abordado na escola livre das amarras do preconceito na busca da construção de uma ética autônoma que respeite os direitos e a expressão das questões da sexualidade humana.

\section{A representação social e o gênero: alguns apontamentos}

Compreende-se que as representações sociais estão vinculadas a valores, noções e práticas individuais que orientam as condutas no cotidiano das relações sociais e se manifestam através de estereótipos, sentimentos, atitudes, palavras, frases e expressões (MOSCOVICI, 2003).

O autor explica que elas são ao mesmo tempo individuais e sociais e as respostas individuais são reflexos das manifestações do grupo social com o qual o sujeito compartilha experiências e vivências da sua vida pessoal, e os pronunciamentos semelhantes revelam certo nível de generalização, uma forma de pensar coletiva sobre um mesmo assunto. Isto denota o dinamismo das representações sociais e sua potencialidade para criar e transformar a realidade social.

Estabelecer uma conexão entre a perspectiva de gênero, homossexualidade e as representações sociais, implica em pensar na concepção da natureza humana, que não se determina somente pelo aspecto biológico, mas envolve uma construção social, histórica e 
cultural. Essa concepção constitui a base da perspectiva de gênero compreendida como um sistema de signos e símbolos que denota relações de poder e hierarquia entre os sexos e no interior de relações do mesmo sexo (SCHIEBINGER, 2001).

Portanto, o autor conclui que a representação social é uma relação de natureza assimétrica que se realiza culturalmente, por ideologias que tomam formas específicas em cada momento histórico.

Assim, o caráter histórico, atribuído ao conceito de gênero, decorrente da sua construção social, evidencia a existência de diversificações dos binômios masculino/feminino e homem/mulher na sociedade. Logo, estudar a perspectiva de gênero e de homossexualidade nas representações sociais das professoras revela o interesse em entender como essas docentes lidam com estas questões no cotidiano, e como as construções socioculturais interferem na sua prática pedagógica. Este entendimento, por sua vez, poderá ajudar a pensar em mudanças nas condutas das instituições escolares, de forma a atender especificidades individuais e de grupos formados por homens e mulheres, em distintos contextos socioculturais.

\section{A pesquisa etnográfica em Educação}

Este estudo utilizou a metodologia baseada na pesquisa Etnográfica em Educação, que possibilita documentar o não-documentado, desvelar lacunas existentes no cotidiano e práticas dos sujeitos permitindo descrever as ações e as representações dos seus atores sociais, reconstruindo sua linguagem, suas formas de comunicação e os significados que são criados e recriados no seu fazer cotidiano pedagógico e entender como atuam, os seus mecanismos de dominação e de resistência, de opressão e de contestação, e ao mesmo tempo, observar as representações dos atores sociais impregnadas das crenças, valores, modos de ver e de sentir a realidade e o mundo (ANDRÉ, 1995).

A pesquisa do tipo etnográfica não pode se limitar à descrição de situações, ambientes, pessoas, ou à reprodução de falas e de seus depoimentos, e sim ir além, tentando reconstruir as ações e interações dos atores sociais segundo seus pontos de vista, suas categorias de pensar, sua lógica, buscando significações do outro, pois o investigador deve ultrapassar seus métodos e valores, admitindo outras lógicas de entender, conceber e recriar o mundo (ANDRÉ, 1995).

Portanto, buscou-se nesse estudo etnográfico apreender e descrever as representações das professoras e os significados culturais que tem em relação questão do gênero e homossexualidade. 


\section{A pesquisa de campo: alguns resultados}

As (os) pesquisadoras (os) permaneceram na escola durante o primeiro semestre (fevereiro a junho de 2009), como citado anteriormente objetivando analisar as representações das professoras sobre gênero e homossexualidade. Realizou-se para a obtenção dos dados a aplicação de um questionário aberto e a redação de diário de campo. Os resultados serão apresentados e refere-se especificamente, as análises do questionário aplicado. Ressalta-se que este trabalho encontra-se em desenvolvimento.

A seguir, serão apresentados os resultados obtidos na análise do material. A Tabela 1 mostra dados relevantes a respeito da necessidade de formação do docente para se trabalhar com as questões de gênero e de homossexualidade em sala de aula.

Tabela 1 - Análise temática: necessidade de Formação ( $\mathrm{N=}$ =corrências).

\begin{tabular}{|c|c|c|c|}
\hline CATEGORIA & SUBCATEGORIA & EXEMPLOS & $\mathbf{N}$ \\
\hline $\begin{array}{l}\text { Necessidade de } \\
\text { Formação }\end{array}$ & $\begin{array}{l}\text { Métodos para trabalhar em } \\
\text { sala de aula }\end{array}$ & $\begin{array}{l}\text { “Difícil, acredito que tenho que ter uma } \\
\text { preparação através de estudos para me } \\
\text { posicionar melhor [...]” Participante (3) }\end{array}$ & 11 \\
\hline & $\begin{array}{l}\text { Do professor para trabalhar o } \\
\text { tema }\end{array}$ & $\begin{array}{l}\text { “[...] Após Estudos, reflexões e discussões } \\
\text { sobre o tema eu proporcionaria brinquedos } \\
\text { para trabalhar a temática com os alunos” } \\
\text { Participantes (4) }\end{array}$ & 39 \\
\hline
\end{tabular}

A análise do material revelou que as professoras possuem pouco conhecimento científico a respeito dos temas, possuindo representações sociais marcadas por uma forte influencia cultural que dificulta a abordagem das temáticas em sala de aula. As participantes revelaram ter dificuldades de trabalhar esses assuntos e quando os abordam, é de maneira tímida, sem permitir uma reflexão, uma problematização que permita a criança se conscientizar, por exemplo, que o gênero é um conceito formado por conhecimentos do senso comum e construído por valores culturais e sociais.

Nas salas dos professores, no momento em que as docentes estavam descontraídas, sem considerar a presença dos (as) pesquisadores (as), estas expressaram visões e concepções contrárias as suas respostas dadas no questionário. Nota-se que essa postura também, é 
presente nos corredores, em conversas informais entre as docentes quando desabafam a respeito de alunos (as) com comportamentos “desfavoráveis” como: “Nossa! as meninas estão piores do que os meninos" [...] "hoje as meninas não se comportam como antes”. (participante 1).

Isso denota que as professoras estão arraigadas no modelo normatizante do gênero feminino e masculino, no qual, ressaltam que as meninas devem ter bons comportamentos e boas atitudes e refere-se como característica inata dos meninos, serem peraltas.

Percebeu-se ainda nos diálogos informais a aflição das docentes em relação a como trabalhar as questões da sexualidade com as crianças, pois expressam serem elas "mais espertas e sabem mais do que nós a respeito de sexo” (Participante 4) e ainda (Participante 1) completou dizendo que "essas coisas de homem com homem e mulher com mulher é o fim do mundo”.

Apesar de evidenciada a dificuldade de trabalhar com temáticas referentes à sexualidade, as professoras nas respostas dadas no questionário, a respeito de como agiriam se uma criança dissesse que menina brinca de boneca e o homem brinca de carrinho, revelam que é preciso conversar e refletir a respeito do assunto, pois essa concepção de gênero é devido a uma construção cultural, como mostra o exemplo a seguir: "Levaria-os a reflexão: Um brinquedo ou uma cor determina o sexo de uma pessoa? Deixaria de ser menino ou menina, por estar brincando de boneca ou carrinho? (Participante 4).

As repostas das docentes a respeito da concepção de homossexualidade mostram que as mesmas julgam, a partir de padrões culturais próprios e normatizantes de comportamentos e revelam preconceitos e tabus, relacionados com o estereótipo, que consiste na generalização e atribuição de valor, apesar de ressaltarem que cada indivíduo tem direito de expressar sua sexualidade como quiser, como mostra a seguinte resposta: “ Não, penso que cada indivíduo de comportar de maneira que quiser, cada um com sua personalidade, jeito de ser... Porém, me assusta ainda cenas explícitas de carícias entre homossexuais em lugares públicos” (Participante 3).

Desta forma, percebe-se que as professoras reconhecem ser que as questões de gênero uma construção sócio-culutral, mas revelam dificuldades de aceitar e tratar a homossexualidade, necessitando de estudos e discussões a respeito do assunto, vislumbrando desconstruir e construir novas representações que possibilitem criar subsídios que contribuam com a prática docente, objetivando formar cidadãos críticos e reflexivos quanto essa questão polêmica, que perpassa a sociedade. 
A Tabela 2 a seguir apresentará dados referentes ao preconceito existente na própria formação cultural e familiar das docentes manifestadas nas respostas do questionário.

Tabela 2 - Análise temática: Preconceito (N=ocorrências)

\begin{tabular}{l|l|l|c}
\hline CATEGORIA & SUBCATEGORIA & EXEMPLOS & N \\
\hline Preconceito & Assunto de difícil & $\begin{array}{c}\text { “...] é um assunto muito complicado de se } \\
\text { abordar e até mesmo de aceitar [...] existe }\end{array}$ & 31 \\
& aceitação/ abordagem & $\begin{array}{l}\text { grande preconceito, inclusive por mim } \\
{[\ldots] ” \text { Participante (1) }}\end{array}$ &
\end{tabular}

Os resultados demonstram o preconceito que as docentes apresentam, mediante a maioria narrar e compreender que é as questões de gênero e a homossexualidade são assuntos assustadores, de difícil aceitação e abordagem, que suscitam preconceitos, discriminações, devido aos valores construídos socialmente, principalmente, quando se enfoca a questão da homossexualidade.

Para um trabalho consistente de Orientação Sexual na escola, os professores precisam participar de projetos que visem à formação docente lhes oferecendo subsídios para trabalharem as questões que atrelam o gênero em sala de aula.

Algumas professoras, participantes do estudo, disseram concordar com as concepções sobre o gênero, e da homossexualidade, mas, o que se revelou implicitamente, foi o preconceito, a preocupação com valores sociais e com possíveis reações desencadeadas nas famílias quando essas temáticas são abordadas na escola, ou quando há algum fato que mereça intervenção, problematização e reflexão, como mostra a resposta a seguir:

Procuraria dizer que temos que respeitar as pessoas com as quais convivemos [...] é um assunto ainda muito complicado de se abordar e até mesmo de aceitar [...] existe um grande preconceito inclusive por mim [...] ainda é difícil aceitar. Enquanto está longe em famílias alheias, mesmo que estranho, ainda se compreende. Penso que no momento que essa situação pode ser vivida por pessoas próximas, aumenta o nível de complicação e a dificuldade em compreender. (Participante 1).

Identificou-se que as docentes evitam discutir assuntos com os (as) alunos (as) contrários a heteronormatividade, como pode-se notar na narrativa da Participante 1 ao relatar ter na sala dos professores (as) ter um aluno com comportamento afeminado e uma história familiar “comprometedora”, pois seu irmão homossexual foi morto devido ao preconceito. Percebe-se que a escola, nesse sentido, reproduz os valores socialmente construídos em 
relação à questão da homossexualidade e esse preconceito encontrado vira discriminação e pode gerar alguma forma de violência.

Assim, o gênero e a homossexualidade são questões complexas de serem discutidas, devido aos princípios morais que os permeiam, os quais são instituídos pela sociedade. Baseado nesse pressuposto pode-se entender a postura da Participante 1 ao orientar o aluno em relação ao seu comportamento afeminado, pois essa docente se apóia no modelo heteronormatizante estabelecido pela sociedade, devolvendo ao aluno a responsabilidade do preconceito social que ele venha a sofrer incentivando-o a modificar seu comportamento para não ter o mesmo desfecho do irmão, ou seja, ter um comportamento heteronormatizante, para não ser vítima de preconceito e de violência.

Depreende-se que não se faz educação de qualidade sem uma educação cidadã, a qual valorize a diversidade. È notório que a escola e seus pares, conservam conceitos normatizadores, homogenizadores e heteronormatizantes que precisam ser revistos.

Essa concepção de educação justificou e justifica, ainda hoje, a fala de educadores e educadoras, os quais, ainda que reconheçam a existência de discriminação dentro e fora da escola, acreditam que é melhor “silenciar”, pois, falar do tema suscitará questionamentos, como revela a Participante 1: “[...] muitas crianças contarão aos pais e esses, por sua vez, virão saber o que está acontecendo [...]”.

Nesse viés Castro (2005) argumenta que é preciso estimular e alertar os professores e as professoras, para o exercício de uma educação cidadã e aceitando as diversidades, rejeitando idéias, comportamentos anti-racista, anti-sexista, anti-homofóbico respeitando o direito dos indivíduos, em expressar sua sexualidade.

Nesse sentido, as docentes reivindicam continuação do projeto ao tomarem ciência de suas fragilidades diante da manifestação das questões a cerca do gênero e da homossexualidade que ocorrem no espaço escolar, pois revelam a necessidade de formação através de estudos que subsidiem a sua prática pedagógica.

\section{Considerações}

Os resultados das análises possibilitaram compreender que as docentes apresentam uma visão simplista, com pouco conhecimento científico em relação às temáticas gênero e homossexualidade, reportando-se às valores morais e sócio-culturais fortalecido pelo modelo heteronormativo e admitem a existência de problemáticas no âmbito escolar, a respeito desses assuntos e evidenciam a necessidade de conversar e refletir. 
As mesmas demonstram conhecimento de que o gênero é uma construção cultural, mas, ressaltam ter dificuldades em abordá-lo, e quando o fazem, é de maneira tímida, sem permitir uma reflexão e problematização, ou seja, possuem representações sociais marcadas por forte influência cultural, reforçando o modelo normatizante do gênero feminino e masculino.

Em relação à homossexualidade, as docentes apreendem a necessidade de estudos e discussões a esse respeito objetivando desconstruir e construir novas representações que possibilitem criar subsídios que contribuam com a prática docente e salientam que esta dificuldade pode estar relacionada à formação rígida, preconceituosa advinda dos valores familiares e sociais. Reconhecem a existência de discriminação dentro e fora da escola, mas, acreditam que silenciar é a melhor estratégia para evitar questionamentos e nesse sentido, evitam, de qualquer forma, discutir assuntos com os (as) alunos (as) referentes à opção sexual diferente dos padrões heteronormatizantes.

Segundo Sousa (2005) estas questões podem gerar angústias nas professoras por maior conhecimento, por mais saber, melhor formação e melhor escola, o que pode refletir na melhora da convivência da própria sexualidade.

Figueiró (2006) a esse respeito avalia que a forma pela qual se conduz a proposta de formação continuada de educadores sexuais, firmada em um modelo reflexivo, comprova a eficácia da reflexão como instrumento de desenvolvimento do pensamento e da ação. Assim, faz-se necessário que sejam abertos espaços de discussões e reflexões sobre Sexualidade, visando amenizar temores e dissipar receios.

Assim, depreende-se ser necessário o desenvolvimento de um trabalho consistente de Orientação Sexual na escola, com a efetiva participação de todos os envolvidos no processo escolar em projetos que visem trabalhar as questões que atrelam o gênero e a homossexualidade na instituição escolar. Nesse sentido, as docentes reivindicam continuação do projeto ao tomarem ciência de suas fragilidades diante da manifestação das questões a cerca do gênero e da homossexualidade que ocorrem no espaço escolar, pois revelam a necessidade de formação através de estudos que subsidiem a sua prática pedagógica.

\section{UNDERSTANDING GENDER: A HIGH SCHOOL TEACHERS VIEW}

ABSTRACT: This paper contains a few reflections about gender and homosexuality conceptions approached at schools by the teachers. This paper is a summary of a project called Body this Unknown developed with teachers of a school in the state of Sao Paulo. The study is referenced by the Social Representations Theory and it aims to discover the social 
representations of eight teachers, related to the matters of gender and homosexuality expressed at school. To obtain the data an open questionary was used, and also the writing of a field journal based on the school ethnographic research methodology. The obtained material was categorized and organized in two charts with respective thematic unities. The analysis of the material revealed that the teachers have little scientific knowledge regarding the themes, and possess social representations marked by cultural influence which makes approaching the subject difficult, and when the subject is approached, it is done in a shy manner, that does not allow for reflection and questioning. They prove to be rooted in the normalizing model of the female and male genders, although they highlight the need to talk and reflect on the matter. Homosexuality appears to be difficult to talk about, because they refer to it in stereotypical and discriminatory ways. The teachers demanded the continuation of the project when they realized their weaknesses regarding these issues, because the research highlighted the need for training through studies that aid their pedagogic profession. It appears to be necessary the effective participation of all involved in this project to work on issues that relate to gender and homosexuality.

KEYWORDS: Gender. Heteronormativity. Teacher formation.

\section{REFERÊNCIAS}

ANDRÉ, M. E. D. A. Etnografia da prática escola. Campinas: Papirus, 1995.

BARDIN, L. Análise de conteúdo. Lisboa: Edições 70, 1995.

BRASIL. Secretaria da Educação Fundamental. Parâmetros Curriculares Nacionais: terceiro e quarto ciclo: apresentação dos temas transversais. Brasília: MEC: SEF, 1998.

CASTRO, M. G. Gênero e raça: desafios à escola. In: SANTANA, M. O. (Org). Lei 10.639/03: educação das relações étnico-raciais e para o ensino da história e cultura afrobrasileira e africana na educação fundamental. Salvador: Prefeitura Municipal de Salvador, 2005.

FIGUEIRÓ, M. N. D. Formação de educadores sexuais: adiar não é mais possível. Londrina: Ed. da UEL, 2006.

FOUCAULT, M. A. História da sexualidade: A vontade de saber. Tradução de Maria Thereza da Costa Albuquerque e J. A. Guilhon Albuquerque. Rio de Janeiro: Edições Graal, 1998. v.1

KAHHALE, M. P. Subsídios para reflexão sobre sexualidade na adolescência. In: BOCK, A. M. B.; GONÇALVES, M. G. M.; FURTADO, O. (Org.). Psicologia sócio-histórica: uma perspectiva crítica em psicologia. São Paulo: Cortez, 2001. p.179-191. 
LÜDKE, M.; ANDRÉ, M. Pesquisa em educação: abordagens qualitativas. São Paulo, E.P.U, 1986.

MOSCOVICI, S. Representações sociais: investigações em psicologia social. Petrópolis: Vozes, 2003.

SCHIEBINGER, L. O feminismo mudou a ciência? Bauru: EDUSC, 2001.

SOUSA, C. P. de. A escola como instituição pensante. In: MENIN, M. S. de S.; SHIMIZU, A. de M. (Org.). Experiências e representação social: questões teóricas e metodológicas. São Paulo: Casa do Psicólogo, 2005. p.247-266. 